\title{
Review Paper on Experimental Study on the use of Modified Bitumen using E-Waste as a Partial Replacement of Aggregate
}

\author{
Manjay Kumar Singh1, Pratiksha Malviya² \\ ${ }^{1}$ M.Tech. Scholar, ${ }^{2}$ Professor \\ Department of Civil Engineering, Millennium Institute of Technology \& Science, \\ Bhopal, Madhya Pradesh, India
}

\begin{abstract}
How to cite this paper: Manjay Kumar Singh | Pratiksha Malviya "Review Paper on Experimental Study on the use of Modified Bitumen using E-Waste as a Partial Replacement of Aggregate" Published in International Journal of Trend in Scientific Research and Development (ijtsrd), ISSN: 24566470, Volume-3 | Issue-3 , April 2019, pp.380-381, URL:

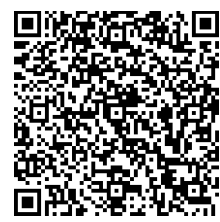
http://www.ijtsrd.com/papers/ijtsrd22 864.pdf
\end{abstract}

Copyright (C) 2019

by author(s) and

International

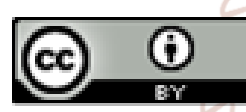

Journal of Trend in Scientific Research and Development Journal. This is an Open Access article distributed under the terms of the Creative Commons Attribution License (CC BY 4.0) (http://creativecommons.org/licenses/ by/4.0)

\begin{abstract}
Literature Survey
Vasudevan et. al [2014], exhibited an investigation on the readiness of plastics squander - bitumen mix and its properties to discover the appropriateness of the mix for street development, was completed. A changed procedure was produced and the stone total was covered with liquid plastics and the plastics squander covered total (PCA) was utilized as the crude material for adaptable development. PCA demonstrated better restricting property. It had less wetting property. Its voids were substantially less. The example demonstrated higher Marshall Solidness esteem. The streets laid utilizing PCA are performing admirably. A point by point considered is exhibited.
\end{abstract}

Vasudevan, et al. [2015] likewise watched that the polymer mixed bitumen has better properties with respect to Softening point, Entrance point, Flexibility, Stripping Quality and Marshall Security esteem. Thus the mix can be utilized for laying adaptable asphalt. In this investigation both dry and wet procedures were utilized to get ready adjusted bituminous blends. In the wet procedure, the mixing was done by straightforwardly blending the destroyed polymer with hot bitumen at $160 \mathrm{deg}$. C. In the dry procedure, a novel system was utilized to utilize higher level of waste plastics in street development and utilizing this strategy a substitute technique was utilized. In this technique, the waste polymer was included the hot total (170deg.C). The polymer was covered over the total. Here the spreading was simple. The hot total was covered with polymer consistently. At that point the Bitumen was included. The blending of bitumen with polymer was occurring at the surface of the total. The temperature was around $155-163 \mathrm{C}$. Both the polymer and bitumen were in the fluid state.

Vasudevan et al [2016] displayed that plastic waste comprising of convey sacks, containers and thermocoles can be utilized as a covering over total and this covered stone can be utilized for street development. By this procedure a street of $1 \mathrm{Km}$ length and $3.375 \mathrm{M}$ width of single path can expends 10, 00000 convey sacks and the street quality is expanded by $100 \%$ and there is no pot opening arrangement. Infiltration was diminished to a low esteem and correspondingly the pliability. It has been construed that the utilization of higher rate (over 3\%) of plastics in polymer altered bitumen isn't good. The paper additionally contemplates utilization of scrap elastic waste as bitumen modifier. Squander tires are powdered and the powder is 
mixed with bitumen $(80 / 100)$ warmed to $100-120 \mathrm{oC}$ and blended at speed of $3000 \mathrm{rpm}$ for $2-3$ hours. This mix is utilized alongside plastic covered total. The blend polymer covered total and tire altered bitumen have indicated higher quality. The level of scrap elastic modifier in the blend changes from $1 \%$ to $5 \%$.

Yadav et al [2017] manages the improvement of changed fastener definitions from plastomer and elastomer write squander with a mean to limit non-biodegradable the post customer polymer squander and also ecological peril, to meet this target ten unique examples have been grabbed from a few sorts of waste to cover distinctive classifications of polymeric waste from the household, mechanical and in addition therapeutic waste. Changed cover definitions were at first portrayed according to the pertinent gauges (code of training) to determining their appropriateness for above said application. The physical properties of altered covers are inside as far as possible. Marshall Soundness, backhanded rigidity and crawl modulus conduct have been assessed and talked about in this examination to demonstrate their double advantages like waste minimization and appropriateness of such fasteners to be utilized for Sturdy Street.

Muhammad Karami [2018] The objective of this research is to determine the potential effect on the resilient modulus of asphalt mixtures of using granular Buton Rock Asphalt (BRA) modified binder. The indirect tensile stiffness modulus (ITSM) tests were performed to examine the resilient modulus of unmodified and BRA modified asphalt mixtures for dense graded aggregates of $10 \mathrm{~mm}$ (DG10) and $14 \mathrm{~mm}$ (DG14) based on standard AS-2891.13.1-1995. In these tests, three percentage of BRA natural binder, including $10 \%, 20 \%$ and $30 \%$ by total weight of asphalt binder, were chosen as a substitute for the base asphalt binder in the BRA modified asphalt mixtures, with the purpose of improving the resilient modulus values. According to the test results, the resilient modulus of BRA modified asphalt mixtures was higher as compared to the unmodified asphalt mixtures. A higher percentage of BRA modifier binder content resulted in a higher resilient modulus. Furthermore, the unmodified and BRA modified containing only $20 \%$ BRA modified binder of DG10 were tested under different conditions of temperature, rise time, and pulse period. The results indicated that the BRA modified asphalt mixtures containing 20\% BRA modified binder were less sensitive to the changes in the temperature, traffic volume and loading frequency. In addition, the substitution of $20 \%$ BRA modifier binder reduced the effect of the rest period ratio and loading time on the resilient modulus of the asphalt mixtures.

\section{Problem identification}

$>$ Review of literature has revealed that E-waste causes adverse effects on the environment.

$>$ The eco-Friendly and reliable development for construction consists the use of non-conventional and different waste materials and recycling of waste material and decreasing the use of natural resources.

$>$ The growth in various types of industries together with population growth has resulted in enormous increase in economic activities world-wide.

$>$ Roads now have to be able to service large vehicular movements over diverse landscapes.
$>$ It is very much desirable that lives of roads be long and requires minimal maintenance. Bitumen is most widely used for roads due to its characteristics, includingbetter binding property, etc. Such useful characteristics of bitumen can be further enhanced by adding modifiers to it.

\section{Objective}

The objectives of this study are as follows:

$>$ To analyze the engineering properties of modified bitumen using E-waste in varying percentage.

\section{CONCLUSION}

Marshal Stability values and flow value of bituminous mix are increased due to addition of E-Waste.

\section{REFERENCES}

[1] Justo C.E.G., Veeraragavan A "Utilization of Waste Plastic Bags in Bituminous Mix for Improved Performance of Roads", Centre for Transportation Engineering, Bangalore University, Bangalore, India, April 2002.

[2] K. Aravind, Animesh Das (2006), "Pavement design with central plant hot-mix recycled asphalt mixes", Construction and Building Materials 21, pp.928-936, Elsevier Ltd.

[3] Khan Amjad, Gangadhar, Murali Mohan, Raykar Vinay, "Effective Utilisation of Waste Plastics in Asphalting of Roads". R.V. College of Engineering, Bangalore 1999.

[4] Khanna S.K.Justo C.E.G,A Text Book of Highway Engineering, Nem Chand Publication New Delhi 2001.

[5] Lebbai Sheikna, S.V. SivaPrakash S. Road Construction with Plastic Wastes National Conference on Recent Trends in Engineering Sciences 2011.

[6] Maharashtra pollution control board (2007)," Report on Assessment of Electronic Waste in Mumbai- pune area" south Asia publishing Pvt. Ltd. New Delhi. Chapter 1(3-12), 6(55-56).

[7] Manual for Construction and Supervision of Bituminous works publish by Indian Roads Congress for Department of Road Transport \& Highways, Ministry of Shipping, Road Transport \& Highways New Delhi 2001.

[8] "Ministry of road transport and highway (2001)", Indian Roads Congress, New Delhi; 2001.

[9] Neutag L University Wuppertal, Pavement Research Centre Wuppertal, Germany 2009.

[10] R. Vasudevan, S. K. Nigam, R. Velkennedy, A. Ramalingam Chandranan sekar \& B. Sunderakannan (2007), "Utilization of waste polymer for flexible pavement and easy disposal of waste polymers", Proceedings of the international conference on sustainable solid waste management, CPCB, New Delhi.

[11] Sabina, Khan Tabrez A, Sangita, Sharma D.K., Sharma B.M, Performance Evalution. Of Waste Plastic/ Polymers Modified Bituminious Concrete Mixes, Journal of Scientific and Industrial Research Vol.68, November 2009.

[12] Shankar S., Prasad C.S.R.K., September2009, Evaluation of rutting potential for crumb rubber modified bitumen in asphaltic mixes. Emirates Journal for Engineering Research, 14 (2), pp- 91-95 2009. 